\title{
Cabozantinib: a novel tyrosine kinase receptor inhibitor for the treatment for advanced renal cell carcinoma
}

\begin{abstract}
Cabozantinib is under universal development with Exelixis Corporation, was approved by the U.S. Food and Drug Administration to treat patients with advanced renal cell carcinoma in patients who have been treated previously with antiangiogenic therapy. It inhibits possible activity of receptor tyrosine kinases (RTKs). This manuscript reviews the available information on cabozantinib with respect to its pharmacodynamics and pharmacokinetics.
\end{abstract}

Keywords: cabozantinib, pharmacodynamic, pharmacokinetics
Volume 3 Issue 2 - 2017

\author{
Mayur Porwal,' Arvind Kumar,' Vaibhav \\ Rastogil \\ I Faculty of Pharmacy, IFTM University, India
}

Correspondence: Mayur Porwal, Faculty of Pharmacy, IFTM University, Moradabad, Uttar Pradesh, India, Tel 9719261023, Email porwal_mayur1985@rediff.com

Received: January 27, 2017 | Published: March 0I, 2017
Abbreviations: ARCC, advanced renal cell carcinoma; FDA, food and drug administration; VEGFR, vascular endothelial growth factor receptor; MET, mesenchymal-epithelial transition; FMS, like tyrosine kinase 3; RTKs, receptor tyrosine kinases

\section{Introduction}

Advanced renal cell carcinoma (ARCC) is the most familiar type of kidney tumor. ${ }^{1}$ Cabozantinib (Cabometyx TM, XL184) is a novel FDA approved drug and it is used for treatment of advanced renal cell carcinoma in patients who have been treated previously with antiangiogenic therapy ${ }^{2}$ and was developed by Exelixis Inc. In adults, Cabozantinib also has been approved for the management of ARCC in Europe. ${ }^{3}$

\section{Molecule}

Cabozantinib is an orally active drug with a molecular weight of $501.51 \mathrm{~g} / \mathrm{mol}$ and molecular formula of $\mathrm{C} 28 \mathrm{H} 24 \mathrm{FN} 3 \mathrm{O} 5$. The structure of cabozantinib is given in Figure 1. The chemical structure name is $\mathrm{N}$-(4-(6,7-dimethoxyquinolin-4-yloxy) phenyl)-N-(4-fluorophenyl) cyclopropane-1,1-dicarboxamide. ${ }^{4}$

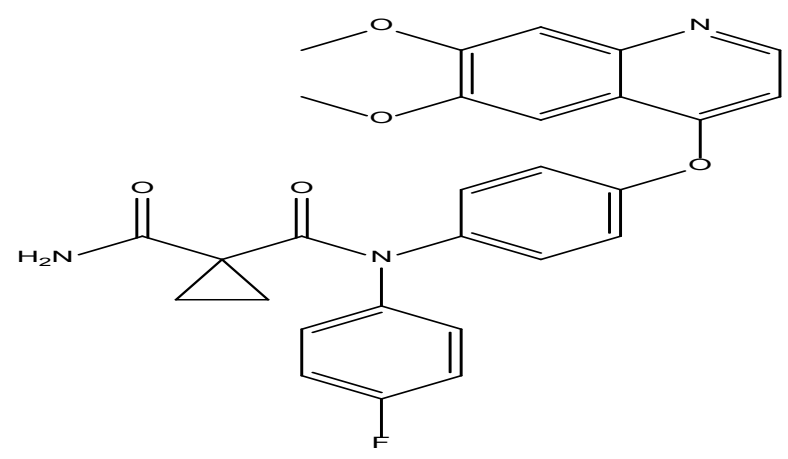

Figure I The structural formula of Cabozantinib.

\section{Pharmacodynamics}

Cabozantinib acts by inhibiting possible activity of receptor tyrosine kinases (RTKs) under attacked at vascular endothelial growth factor receptor types 1 (VEGFR-1), 2 (VEGFR-2) and 3 (VEGFR--3), mesenchymal-epithelial transition factor (MET) but also inhibits the action of many other factors such as FMS-like tyrosine kinase 3 (FLT-3), TIE-2, ROS1, MER and RET., ${ }^{4,5}$ Various features and properties of cabozantinib are listed in Table 1.

\section{Randomized study design}

A phase 3 trial, randomized study, funded by Exelisis (clinical trials no. NCT01865747), was designed to study the efficacy of cabozantinib. Total 658 random recipients were selected to receive the recommended daily dose of cabozantinib $60 \mathrm{mg}$. The end point of study selected was median progression free survival. The results showed approximately 7.8 months, median progression free survival with a lower death rate of approximately $42 \%$. The study also supported a longer overall survival of the patient (statistically supported). The adverse effects of the drug were managed with a reduction in the doses. ${ }^{3}$

\section{Pharmacokinetics}

Absorption: Cabozantinib is an orally active compound, showing the peak plasma concentrations at $5 \mathrm{hrs}$, the plasma half-life of it was $91.3 \pm 33.3 \mathrm{hrs}$. The middle time to achieve Cmax was found 3-4hrs.

Administration of cabozantinib with rifampin showed in upper plasma clearance (4.3-fold higher) and reduce in plasma AUC0-inf of cabozantinib approximately $77 \%$, but administered with the co-administration of ketoconazole, it was obtained that plasma clearance was decreased (29\%) or AUC0-inf was increased (38\%). It does not show significant effect on rosiglitazone maximum plasma concentration (Cmax), AUC0-24, or AUC0-inf. The apparent oral clearance (CL/F) of cabozantinib was found to be $106 \mathrm{~L} /$ day. Cabozantinib showed expected effective half-life (t1/2) around 55 hrs. $^{6-8}$

Distribution: At steady state, the mean apparent volume of distribution of cabozantinib is $349 \mathrm{~L}$. The plasma protein binding of cabozantinib is very high $(\geq 99.7 \%){ }^{9}$

Metabolism: Cabozantinib is metabolized in the liver. Cytochrome P450 (CYP) 3A4 is the primary CYP isoenzyme and responsible for 
metabolism of cabozantinib and it inhibits CYP2C8. Monohydroxy sulfate is the major metabolite of it. ${ }^{7}$

Elimination: Cabozantinib and its metabolites are primarily excreted by the kidneys. Total mean radioactivity recovery was found to be $81.09 \%$ in 48 days. Approximately $27.29 \%$ and $53.79 \%$ of the radioactive dose of cabozantinib was eliminated in urine and feces. ${ }^{9}$

Recommended dose: The recommended dose of cabozantinib for the treatment of advanced renal cell carcinoma is $60 \mathrm{mg}$. Patients should be aware not to administer the drug with foods (citrus fruits or juice, nutritional supplements, etc.) as it may inhibit cytochrome P450 during treatment.

Special instructions: An important instruction must be provided to the patients regarding its administration. Food and other supplements should not be taken before 2 hours and at least one hour after taking cabozantinib. ${ }^{2}$

Table I Some main properties of Cabozantinib

\begin{tabular}{|c|c|}
\hline \multicolumn{2}{|c|}{ Features and properties of Cabozantinib } \\
\hline $\begin{array}{l}\text { Alternative } \\
\text { names }\end{array}$ & CabometyxTM,XLI84,Cometriq \\
\hline Class & CYP3A4 inhibitor \\
\hline $\begin{array}{l}\text { Mechanism of } \\
\text { Action }\end{array}$ & $\begin{array}{l}\text { Receptor tyrosine Kinases, VEGFR-I,VEGFR-2, } \\
\text { VEGFR-3, MET, FLT-3,TIE-2, ROSI, MER and RET } \\
\text { inhibitor }\end{array}$ \\
\hline $\begin{array}{l}\text { Route of } \\
\text { Administration }\end{array}$ & Oral \\
\hline Pharmacokinetic & $\begin{array}{l}\text { Rapid, dose proportional absorption after oral } \\
\text { administration, maximum plasma concentration } \\
\left(\mathrm{C}_{\max }\right) \text { is } 3-4 \mathrm{hrs} \text {, bound to plasma proteins }, \mathrm{T}_{\max } \\
9 \mathrm{I} .3 \pm 33.3 \mathrm{hrs} \text {, Half life is } 55 \text { hrsApproximately } \\
27.29 \% \text { and } 53.79 \% \text { of Cabozantinib was } \\
\text { eliminated in urine and feces }\end{array}$ \\
\hline $\begin{array}{l}\text { Adverse events } \\
\text { Most frequent } \\
\text { (incidence > } \\
5 \% \text { ) }\end{array}$ & Fatigue, diarrhea, weight loss, and transminitis \\
\hline ATC Code & LOIXE26 \\
\hline $\begin{array}{l}\text { Pharmaceutical } \\
\text { Form }\end{array}$ & Tablet, Capsule \\
\hline Chemical Name & $\begin{array}{l}\mathrm{N}-(4-(6,7-\text { dimethoxyquinolin-4-yloxy) phenyl) } \\
-\mathrm{N}-(4-\text { fluorophenyl) cyclopropane- } \mathrm{I}, \mathrm{I}- \\
\text { dicarboxamide }\end{array}$ \\
\hline $\begin{array}{l}\text { Molecular } \\
\text { Formula }\end{array}$ & $\mathrm{C}_{28} \mathrm{H}_{24} \mathrm{FN}_{3} \mathrm{O}_{5}$ \\
\hline $\begin{array}{l}\text { Molecular } \\
\text { Weight }\end{array}$ & $501.51 \mathrm{~g} / \mathrm{mol}$ \\
\hline
\end{tabular}

VEGFR, vascular endothelial growth factor receptor; MET, mesenchymalepithelial transition; FLT-3, FMS-like tyrosine kinase 3

\section{Conclusion}

Cabozantinib's approval was based on the results of a phase III randomized clinical trial comparing the drug with everolimus, which the FDA approved in 2009 for patients with kidney cancer whose disease has progressed after prior treatment.

It is concluded that cabozantinib is an orally active and new anticancer (kinase inhibitor) drug. Cabozantinib was approved for patients with ARCC, previously treated with antiangiogenic therapy by the U.S. Food and Drug Administration (U.S.FDA). Cabozantinib is a novel probable standard of care for the patients of ARCC.

\section{Acknowledgements}

None.

\section{Conflict of interest}

The author declares no conflict of interest.

\section{References}

1. Chow WH, Dong LM, Devesa SS. Epidemiology and risk factors for kidney cancer. Nat Rev Urol. 2010;7(5):245-257.

2. Yu SS, Quinn DI, Dorff TB. Clinical use of cabozantinib in the treatment of advanced kidney cancer: efficacy, safety, and patient selection. Onco Targets Ther. 2016;9:5825-5837.

3. Cabometyx (cabozantinib) filmcoated tablets: EU summary of product characteristics European Medicines Agency. 2016.

4. Wang X, Wang S, Lin F, et al. Pharmacokinetics and tissue distribution model of cabozantinib in rat determined by UPLC-MS/MS. J Chromatogr B Analyt Technol Biomed Life Sci. 2015;(983-984):125-131.

5. Kadi AA, Abdelhameed AS, Darwish HW, et al. Liquid chromatographic-tandem mass spectrometric assay for simultaneous quantitation of tofacitinib, cabozantinib and afatinib in human plasma and urine. Trop $J$ Pharm Res. 2016;15(12):2683-2692.

6. Hart CD, De Boer RH. Profile of cabozantinib and its potential in the treatment of advanced medullary thyroid cancer. Onco Targets Ther. 2013;6:1-7.

7. Nguyen L, Holland J, Miles D, et al. Pharmacokinetic (PK) drug interaction studies of cabozantinib: Effect of CYP3A inducer rifampin and inhibitor ketoconazole on cabozantinib plasma PK and effect of cabozantinib on CYP2C8 probe substrate rosiglitazone plasma PK. J Clin Pharmacol. 2015;55(9):1012-1023

8. Miles D, Jumbe NL, Lacy S, et al. Population Pharmacokinetic Model of Cabozantinib in Patients with Medullary Thyroid Carcinoma and Its Application to an Exposure-Response Analysis. Clin Pharmacokinet. 2016;55(1):93-105

9. Lacy S, Hsu B, Miles D, et al. Metabolism and Disposition of Cabozantinib in Healthy Male Volunteers and Pharmacologic Characterization of Its Major Metabolites. Drug Metab Dispos. 2015;43(8):1190-1207. 